\title{
Dynamic organisational capabilities: The role of authentic leadership and trust
}

\begin{tabular}{|c|c|}
\hline \multicolumn{2}{|c|}{$\begin{array}{l}\text { Authors: } \\
\text { Deon J. Kleynhans }{ }^{1,2} \\
\text { Marita M. Heyns } \\
\text { Marius W. Stander } \\
\text { Mari, }\end{array}$} \\
\hline \multicolumn{2}{|c|}{$\begin{array}{l}\text { Affiliations: } \\
{ }^{1} \text { Optentia Research Focus } \\
\text { Area, Faculty of Humanities, } \\
\text { North-West University, } \\
\text { Vanderbijlpark, South Africa }\end{array}$} \\
\hline \multicolumn{2}{|c|}{$\begin{array}{l}\text { ²Department of Human } \\
\text { Resource Management, } \\
\text { Faculty of Economic } \\
\text { Management Sciences, } \\
\text { North-West University, } \\
\text { Vanderbijlpark, South Africa }\end{array}$} \\
\hline \multicolumn{2}{|c|}{$\begin{array}{l}{ }^{3} \text { Department of Industrial } \\
\text { Psychology, Faculty of } \\
\text { Economic Management } \\
\text { Sciences, North-West } \\
\text { University, Vanderbijlpark, } \\
\text { South Africa }\end{array}$} \\
\hline \multicolumn{2}{|c|}{$\begin{array}{l}\text { Corresponding author: } \\
\text { Marita Heyns, } \\
\text { Marita.Heyns@nwu.ac.za }\end{array}$} \\
\hline \multicolumn{2}{|c|}{$\begin{array}{l}\text { Dates: } \\
\text { Received: } 21 \text { Jan. } 2021 \\
\text { Accepted: } 04 \text { July } 2021 \\
\text { Published: } 27 \text { Aug. } 2021\end{array}$} \\
\hline \multicolumn{2}{|c|}{$\begin{array}{l}\text { How to cite this article: } \\
\text { Kleynhans, D.J., Heyns, } \\
\text { M.M., \& Stander, M.W. } \\
\text { (2021). Dynamic } \\
\text { organisational capabilities: } \\
\text { The role of authentic } \\
\text { leadership and trust. SA } \\
\text { Journal of Industrial } \\
\text { Psychology/SA Tydskrif } \\
\text { vir Bedryfsielkunde, } \\
\text { 47(0), a1877. https://doi. } \\
\text { org/10.4102/sajip.v47i0.1877 }\end{array}$} \\
\hline \multicolumn{2}{|l|}{ Read online: } \\
\hline 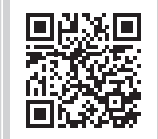 & $\begin{array}{l}\text { Scan this QR } \\
\text { code with your } \\
\text { smart phone or } \\
\text { mobile device } \\
\text { to read online. }\end{array}$ \\
\hline
\end{tabular}

Orientation: The world of work has become unstable and precarious, thereby accentuating the need to maintain dynamic capabilities such as sensing, seizing and reconfiguring to adapt and thrive. Associated challenges potentially threaten the well-functioning of organisations and their employees. This problem might be alleviated by encouraging the leaders to be more authentic, resulting in various positive outcomes.

Research purpose: The aim of the study was to assess the associations authentic leadership (AL) have with trust in organisation (TO), trust in colleagues (TC) and dynamic organisational capabilities (DC) such as sensing, seizing and reconfiguring as these manifest within a context of extreme volatility.

Motivation for the study: Having a high level of DC might contribute to the feasibility of successful organisations in the struggling manufacturing industry, as it could enhance their sustainability and competitiveness.

Research approach/design and method: A quantitative cross-sectional survey design was used. The Authentic Leadership Inventory, Workplace Trust Survey and Dynamic Capabilities questionnaire were administered.

Main findings: AL positively associates with TO, TC and DC. The direct effect of AL on DC was further enhanced through both TO and TC as underlying mechanisms.

Practical/managerial implications: Manufacturing industry organisations should promote an AL style as it will contribute to higher levels of TO, TC and eventually improved DC.

Contribution/value-add: Our study highlights the association of AL with DC as an important outcome. Insight into the underlying mechanisms by which AL achieves effect is advanced through trust, simultaneously targeting interpersonal as well as organisational levels as foci.

Keywords: authentic leadership; trust in the organisation; trust amongst colleagues; dynamic organisational capabilities; sensing; seizing; reconfiguring.

\section{Introduction}

\section{Orientation}

The world of work, as we know it, has transformed dramatically during the last decade and is characterised by continuous renewal and change (Robbins, Judge, Odendaal, \& Roodt, 2016). Henryhand (2009) maintained that organisations find it increasingly difficult to remain competitive as new economic and business challenges continue to emerge. The economic turbulence and the rapid pace of change in the business environment exacerbate uncertainty and are throwing many leaders off-balance as they find it increasingly difficult to give direction under these circumstances (Raghuramapatruni \& Kosuri, 2017).

Although most organisations across the globe are affected by these realities, the companies within the borders of South Africa (SA), which is a developing country, might be more susceptible to these negative external pressures. As an example, the South African manufacturing industry, more specifically the steel-making sector, has been plagued by challenging economic, market and operational challenges. During the second quarter of 2020, the manufacturing industry decreased by $74.9 \%$ and its contribution to the South African gross domestic product (GDP) was $-10.8 \%$ (Statistics South Africa, 2020). In order to stay afloat, the sector had to embark on numerous restructuring and staff reduction initiatives over the past few years. This resulted in leaders finding it increasingly difficult to maintain employee trust and secure organisational competitiveness. 
Hung, Yang, Lien, McLean and Kuo (2010) stated that the activity of maintaining a competitive advantage is dynamic; hence, proponents have suggested that for an organisation to remain competitive in a challenging business environment, the entity needs to develop, amongst others, dynamic organisational capabilities (DC) (Wilden, Gudergan, Nielsen, \& Lings, 2013). In support of this view, Teece (2014) posited that DC can be a source of competitive advantage. The term dynamic capabilities refers to the capacity of an organisation to purposefully generate, expand or modify its resource base (Helfat et al., 2007).

The social context within an organisation shapes the attitudes, behaviours and interpersonal relationships amongst the role players and enables the adaptability and coordination that drives DC (Argote \& Ren, 2012). The foundational climate for trust is of interest in this study as it has the potential to reinforce adaptability and coordination amongst organisation members (Carroll, Gormley, Bilardo, Burton, \& Woodman, 2006; Collins \& Smith, 2006), that could enhance DC (Kleinbaum \& Stuart, 2014). Additionally, DC may be enabled by trusting relationships within an organisation (Helfat \& Peteraf, 2015; Pablo, Reay, Dewald, \& Casebeer, 2007). These findings suggest that trust has the potential to serve as an underlying process through which the effect of Authentic Leadership (AL) on DC takes shape.

Furthermore, Lewicki, McAllister and Bies (1998) maintained that trust is deemed vital in an uncertain business environment as employees utilise perceptions of trust as a method of dealing with challenges in their work environment. Additionally, Saruhan (2013) found that in the mentioned context, employees might find it difficult to have trust in the organisation (TO) and these circumstances may result in them feeling insecure and uncertain. Uncertainty in the workplace could also result in feelings of mistrust towards supervisors and colleagues (Islam, Furuoka, \& Idris, 2020; Thanetsunthorn \& Wuthisatian, 2020; Villena, Choi, \& Revilla, 2019).

Given the above-mentioned reality, Anuradha and Sujatha (2019) stated that the success of leaders functioning in this uncertain context is based on sound business principles, an organisation's ability to respond speedily, robust collaborative networks and trusting relationships, innovation and ethical practices. To this end, AL has attracted scholars' attention because of its claimed positive influence on various employee and organisational outcomes (Avolio \& Walumbwa, 2014; Gardner, Cogliser, Davis, \& Dickens, 2011; Towsen, Stander, \& Van der Vaart, 2020; Wang \& Hsieh, 2013). As an example, Stander, De Beer and Stander (2015) mentioned that AL will predict positive work-related outcomes, more specifically the outcome of TO, which is one of the focus areas of this study. Moreover, authentic leaders can cultivate credibility and trust amongst employees through the authenticity they display (Bamford, Wong, \& Laschinger, 2013).
It is proposed that an AL style will enhance DC because of its positive influence on employee innovation and creativity (Muceldili, Turan, \& Erdil, 2013; Rego, Sousa, Marques, \& Cunha, 2014; Ribeiro, Duarte, Filipe, \& Torres de Oliveira, 2020), information- and knowledge-sharing (Černe, Jaklič, \& Škerlavaj, 2013; Rego, Sousa, Marques, \& Cunha, 2012) and decision-making and problem-solving (Gaddy, Gonzalez, Lathan, \& Graham, 2017). Despite the potential value that DC might have to contribute to the competitive advantage of an organisation, the relationship between AL and DC has not yet been sufficiently explored. Additionally, nor has the underlying mechanisms through which the relationship between AL and DC can potentially be strengthened been adequately researched in previous studies.

Although the potential value of adopting a leadership approach such as AL in a business setting has been investigated in several research studies (Azanza, Moriano, Molero, \& Mangin, 2015; Coxen, Van der Vaart, \& Stander, 2016; Khan, 2010; Munyaka, Boshoff, Pietersen, \& Snelgar, 2017), little empirical work has been conducted to evaluate the role of authentic leadership in a South African manufacturing environment. This represents an important research gap in South African literature. It will be of value to investigate the application of AL within the mentioned context as it is currently functioning in a turbulent environment that accentuates the precariousness of both the organisation, in terms of its sustainability, and its employees, who are faced with uncertainty regarding continued employment.

\section{Research purpose and value-add}

The study aimed to answer the following main research question: What is the relationship between $\mathrm{AL}$, trust (in the organisation and amongst colleagues) and DC?

Firstly, the study adds value because it could assist in better understanding about how AL is experienced within a developing country context. This becomes of even more interest because the sector within which the study is situated, namely the steel manufacturing sector of SA, is currently experiencing extreme turbulence that puts this leadership style and its impact on important outcomes to the test. Would AL be able to build the dynamic capabilities of the organisation despite the prevalent economic challenges? Because employees of the organisation are constantly confronted with the realities of restructuring and even possible retrenchment, the study provides more insight into the effect that the aforementioned realities might have on trust in the organisation (TO) and trust in colleagues (TC).

\section{Literature review}

\section{Authentic leadership}

Authentic leadership as a concept in leadership literature has been studied within the limits of modern leadership theories (Chan, Hannah, \& Gardner, 2005). Wang, Sui, Luthans, Wang and $\mathrm{Wu}$ (2014) stated that AL is characterised by a leader's 
conduct that demonstrates self-awareness, relational transparency, balanced processing and internalised moral perspective. Self-awareness refers to the awareness of one's strengths and weaknesses, as well as values and beliefs (Avolio \& Gardner, 2005). Relational transparency refers to presenting one's true self to others, resulting in the establishment of trust and cooperation, and nurturing teamwork amongst co-workers (Gardner, Avolio, Luthans, May, \& Walumbwa, 2005). Balanced processing points to a leader's ability to be unbiased in considering all relevant information before reaching a decision (Leroy, Palanski, \& Simons, 2012). Lastly, internalised moral perspective refers to a leader's moral values and beliefs that are compatible with his or her behaviour (Walumbwa, Avolio, Gardner, Wernsing, \& Peterson, 2008). Neider and Schriesheim (2011) maintained that the behaviour exhibited by authentic leaders is characterised by their inspiration and motivation of others, their stimulation of others on an intellectual level and their provision of individualised attention to followers. These features enable the followers to thoroughly analyse their authentic leader's principles and proficiency based on the actions of their leader (Wang et al., 2014).

\section{Authentic leadership and trust (in organisation and amongst colleagues)}

Stander et al. (2015) pointed out that TO is a highly soughtafter organisational state - for instance, it has been associated with various positive outcomes such as work engagement (Gillis, 2003), knowledge sharing amongst team members in an organisation (Ferres, Connell, \& Travaglione, 2005) and employee performance (Paliszkiewicz \& Koohang, 2013). It is thus important for leaders - regardless of their leadership style - to strive to promote trusting relationships with their followers.

Authentic leadership represents authenticity as well as positive empowering behaviours which will result in employees being more willing to trust their employers (Stander et al., 2015). Avolio Gardner, Walumbwa, Luthans and May (2004) further stated that AL enables social interplay between leader and follower in a culture that reinforces the sharing of information and open communication. The aforementioned results in $\mathrm{TO}$, as the authentic nature of the leadership approach, culminate in transparency and the sense that the organisation, through its leaders, has the best interests of employees at heart (Gardner et al., 2005). Trust in organisation, as described by Gilbert and Tang (1998), is a sense of support towards and confidence in one's employer as well as a conviction an employee holds that the organisation that employs them has their best interest at heart. Bromiley and Cummings (1996) posited that when employees have trust in their organisation, they will invest energy and effort to help ensure that the organisation's objectives are successfully achieved.

When authentic leaders display authenticity through their words and actions, they can foster respect, credibility and trust amongst employees (Bamford et al., 2013). Begley (2006) stated that AL is a reciprocal phenomenon as it results in authenticity in the followers and the prospective leaders, who then become authentic in their behaviour. Based on this statement and the fact that authentic leaders create a trustful relationship with their subordinates (Gardner et al., 2005), it is likely that the modelling of AL will also result in increased levels of trust that will be established amongst co-workers.

\section{Authentic leadership and dynamic organisational capabilities}

Dynamic capability is defined as 'the firm's ability to integrate, build and reconfigure internal and external competences to address rapidly changing environments' (Teece, Pisano, \& Shuen, 1997, p. 516). Dynamic capabilities are noticeably different from organisational operations, which describe what the company is currently focussing on. Instead, dynamic capabilities emphasise the potential of the business to develop long-term competitive advantage through the modification of its short-term competitive position (Muldoon, Bendickson, \& Mayherne, 2019). Dynamic capability can also be defined as 'the firm's potential to systematically solve problems, formed by its propensity to sense opportunities and threats, to make timely and market-oriented decisions, and to change its resource base' (Barreto, 2010, p. 270). The two definitions being closely related, the latter definition was used in this study to describe the potential relationship between AL and DC. Although organisations that have enhanced DC are not guaranteed success, it can serve as a potential source of improved organisational performance (Helfat et al., 2007). Gnizy, Baker and Grinstein (2014) concluded that a lack of dynamic capabilities would limit an organisation's ability to maintain its competitive advantage, especially in an uncertain business environment.

Authentic leaders who exhibit self-awareness (act true to themselves), balance their values with external demands and make decisions according to their deep-rooted moral standards (internalised moral perspective), seek and appraise input from various perspectives (balanced processing) and sustain relationships rooted in transparency, authenticity and honesty with followers (relational transparency), have a noticeable influence on positive outcomes (Avolio \& Walumbwa, 2014).

According to the AL theory, authentic leaders can encourage innovation and creativity by motivating their followers to exhibit more daring and imaginative behaviour (Avolio et al., 2004). Furthermore, high levels of relational transparency make it possible for managers to openly display support and show that they value the capabilities of employees and want them to perform well (Zhou, Ma, Cheng, \& Xia, 2014). Therefore, such leaders build strong relations with their subordinates, who then may be more willing to share their ideas and find different ways of solving problems (Laguna, Walachowska, Gorgievski-Duijvesteijn, \& Moriano, 2019). Authentic leaders are also open and honest communicators who willingly share information with their followers 
(Joo \& Jo, 2017). The shared information enables employees to develop their intuition, broaden their knowledge and acquire new skills (Kirkman \& Rosen, 1999). Authentic leaders are also likely to enable employees to make sound decisions and to solve problems effectively in challenging and problematic situations by placing a focus on employee involvement and participation (Ilies, Morgeson, \& Nahrgang, 2005). In an organisational environment where information and knowledge sharing is established as the norm, the possibility for employees sharing more opinions, suggestions, ideas and, solutions with the leader, because of the leader engaging in participative decision making, is higher (Rawung, Wuryaningrat, \& Elvinit, 2015). These conditions might assist the leader to be more aware of potential threats and opportunities, as well as arrive at an informed decision and the best solution when confronted by challenging situations, which are the two key components of the DC construct.

\section{Authentic leadership, dynamic organisational capabilities and trust (in the organisation and amongst colleagues)}

Authentic leadership can also be defined as a type of leadership behaviour which utilise both positive psychological capacities and an ethical climate to ensure that leaders and followers are cultivating self-awareness, an internalised moral perspective, the balanced processing of information and relational transparency (Walumbwa et al., 2008). Beddoes-Jones and Swailes (2015) found that trust is at the core of AL. Moreover, AL has a significant influence on $\mathrm{TO}$, trust in the supervisor and trust amongst co-workers (Coxen et al., 2016). Miniotaite and Buciuniene (2013) suggested that AL increases followers' TO amongst other positive outcomes. Tabak, Polat, Çoşar and Türköz (2013) found that employees who have a high-level of AL perception reported high levels of organisational trust. This finding upheld the results of the studies conducted by Dasborough and Ashkanasy (2005) and Çeri-Booms (2009) that AL results in increased levels of organisational trust.

According to Bamford et al. (2013), authentic leaders are perceived to demonstrate authenticity and foster respect, credibility and, ultimately, trust amongst subordinates (co-workers). Furthermore, Gill and Caza (2018) posited that trust amongst co-workers could emerge from the authentic culture and climate created by supervisors (authentic leaders) for their subordinates at their workplace.

Fainshmidt and Frazier (2017) found that the dynamic capabilities of sensing, seizing and reconfiguring are influenced by the organisational context which shapes the member interaction within an organisation. A trustful environment (climate for trust) may promote the type of adaptability and coordination amongst organisation members, which results in increased DC and subsequent competitive advantage (Fainshmidt \& Frazier, 2017). Schreyögg and Sydow (2010) further stated that a trustful environment may contribute to the organisation's ability to reflect on the current way things are performed. It might also encourage information- and knowledge-sharing, and change-oriented behaviour and activities throughout the organisation, which may result in the discovery of new opportunities or the reconsideration of current routines as a means to adapt to new conditions (Schreyögg \& Sydow, 2010). Subsequently, a trustful environment (climate for trust), should facilitate the actual reconfiguration of the organisation's resource base requiring minimum cost and friction as it is enabled by the cooperative interactions and adaptability amongst employees (Fainshmidt \& Frazier, 2017).

Based on the foregoing discussion, the main and supporting research questions of this study were formulated as follows:

- What are the effects of authentic leadership on trust (in the organisation and amongst colleagues) and dynamic organisational capabilities?

- Will trust (in the organisation and amongst colleagues) mediate the relationship between authentic leadership and the organisation's dynamic capabilities?

Considering the definition and components of AL as defined in the literature and indicated above, the researchers propose the following: (1) AL is positively associated with DC and (2) the association between $\mathrm{AL}$ and $\mathrm{DC}$ is strengthened by enabling a trustful environment characterised by TO and TC as underlying processes. The following hypotheses were formulated:

Hypothesis 1: AL is positively associated with TO, TC and DC.

Hypothesis 2: TO (a) and TC (b) is positively associated with DC.

Hypothesis 3: AL is positively related to DC through TO (a) and TC (b).

\section{Research design Research approach}

A quantitative approach and a cross-sectional survey design were followed. The current study explored relationships amongst variables that have not been studied in this combination before; hence a cross-sectional design was deemed appropriate (Spector, 2019).

\section{Research method}

\section{Research participants}

The study population comprised employees from three managerial levels consisting of senior, middle and junior managers working at the respective plant sites of a South African manufacturing organisation that is currently undergoing changes in an attempt to increase its performance and sustainability. All participants were proficient in English; either as their first or second language. A total of 570 questionnaires were distributed, of which 314 were completed in full. This represents a response rate of 55\%. A stratified random sampling technique enabled the collection of data. Table 1, as compiled by the authors depicts the characteristics of the participants: $41.7 \%$ of the respondents were in the 51-60 age group and $64.7 \%$ were employed at junior manager level. A total of $33.4 \%$ of the participants had $21-30$ years of 
TABLE 1: Characteristics of participants $(n=314)$.

\begin{tabular}{llcc}
\hline Item & Category & Frequency & $\mathbf{\%}$ \\
\hline Age group & 20-30 years & 7 & 2.2 \\
& $31-40$ years & 39 & 12.4 \\
& $41-50$ years & 126 & 40.1 \\
& $51-60$ years & 131 & 41.7 \\
& $\geq 61$ years & 11 & 3.5 \\
Job category & Senior manager & 41 & 13.0 \\
& Manager & 70 & 22.2 \\
Experience & Junior Manager & 203 & 64.7 \\
& 0-10 years of service & 39 & 12.4 \\
& $11-20$ years of service & 60 & 19.1 \\
& 21-30 years of service & 105 & 33.4 \\
& 31-40 years of service & 96 & 30.5 \\
& 41-45 years of service & 14 & 4.5 \\
Years in current position & 0-10 years & 199 & 63.3 \\
& 11-20 years & 76 & 24.2 \\
& 21-30 years & 27 & 8.6 \\
& 31-40 years & 10 & 3.1 \\
& 41-45 years & 2 & 0.6 \\
\hline Operating area & Vanderbijlpark works & 163 & 51.9 \\
& Newcastle works & 56 & 17.8 \\
& Gauteng operations & 26 & 8.3 \\
& Corporate services & 69 & 22.0 \\
\hline
\end{tabular}

service and a further $30.5 \%$ had $31-40$ years of service. Of the participants, $63.3 \%$ indicated that they had 0-10 years of service in their current position and $24.2 \%$ of the sample had been employed for 11-20 years in their current position.

\section{Measuring instruments}

Consenting participants were requested to complete a biographical questionnaire as well as instruments for measuring $\mathrm{AL}, \mathrm{TO}, \mathrm{TC}$ and $\mathrm{DC}$.

The Authentic Leadership Inventory (ALI) (Neider \& Schriesheim, 2011) was used to measure the employees' perception of the AL characteristics of their direct supervisor. The ALI consists of four dimensions, namely self-awareness (three items), internal moral perspective (four items), balanced processing (four items) and relational transparency (three items), which are measured by 14 items. Example items include: 'My leader clearly states what he/she means' and 'My leader is guided in his/her actions by internal moral standards'. A five-point Likert-type scale ranging from 1 (strongly disagree) to 5 (strongly agree) was applied to score the items. Earlier studies reported acceptable reliabilities with Cronbach's alpha coefficients ranging between 0.74 and 0.90 (Men \& Stacks, 2014; Neider \& Schriesheim, 2011). The reliability of ALI was also determined in a South African study ( $\alpha=0.93$; Stander et al., 2015).

Two scales of the Workplace Trust Survey (WTS) (Ferres \& Travaglione, 2003), were used to measure TC (12 items) and TO (11 items) which were scored applying a seven-point Likert scale ranging from 1 (strongly disagree) to 7 (strongly agree) for each scale. An example item for TO includes the statement 'I have positive feelings about the future direction of my organisation' and an example item for TC includes 'I feel that my co-workers are truthful in their dealings with me' (Ferres \& Travaglione, 2003). Previous studies employing the WTS in both a South African and Australian context have resulted in Cronbach alpha reliability coefficients ranging between 0.90 and 0.97 (Ferres \& Travaglione, 2003).

Dynamic organisational capabilities were measured using the 12 items taken from Wilden et al. (2013), with four items for each of the three components of sensing, seizing and reconfiguring. Example items include: 'In my organisation, we observe best practices in our sector' (sensing); 'In my organisation, we adopt the best practices in our sector' (seizing) and 'In my organisation, we frequently change our marketing method or strategy' (reconfiguring). A sevenpoint Likert-type scale ranging from 1 (strongly disagree) to 7 (strongly agree) was used to record responses. Cronbach alpha coefficients ranging from 0.60 to 0.82 were reported for the three subscales (Wilden et al., 2013).

\section{Research procedure}

Before the commencement of the study, permission was obtained from the Chief Executive Officer of the manufacturing company at which the study was conducted. Additionally, scientific and ethics clearance was secured from a reputable South African institution for higher education. Participants were allowed 4 weeks to complete the electronic questionnaires in their own time and at their own pace.

We acknowledge the risk of common method variance (CMV) incurred through self-reported questionannaires. However, because of our interest in participants' own perceptions (rather than how the objective environment would reflect possible associations between constructs), the use of monomethod self-reports was deemed more appropriate than alternative sources of information (Spector, 2006, 2019). We followed good measurement practice by making use of previously validated measures that have been carefully designed to eliminate item ambiguity. We also structured the context of questions so as to clearly separate the independent and dependent variables and by using different scales in different sections of the questionnaire. We further employed procedural remedies to counter CMV, for example, by asking participants to complete the questionnaire at home (which would help to psychologically distance themselves) and over a rather lengthy period of 4 weeks during which they could complete sections of the questionnaire without doing so in one straight session. A cover letter explained that participation was voluntary and that responses would be anonymised prior to data analysis (rather than merely be treated confidentially) in order to encourage honest answers. Finally, we also employed statistical procedures to test for CMV, which will be discussed further below.

\section{Statistical analysis}

Statistical analysis was performed by utilising Mplus 8.4 (Muthén \& Muthén, 1998-2019). In Mplus, Structural Equation Modelling (SEM) was applied to evaluate the measurement and structural models and to analyse the proposed structural 
paths between the variables. Items of all questionnaires were treated as continuous and because no missing values were recorded, the mean-adjusted Maximum Likelihood (MLM) estimator which is robust to the non-normality of data (Wang \& Wang, 2012), was used as an estimator.

The following fit indices were considered: Absolute fit was assessed by calculating the Chi-square values. Alternative fit indexes such as Root Mean Square Error of Approximation (RMSEA) and Standardised Root Mean Square Residual (SRMR) were also assessed. Values lower than 0.08 are accepted as an indication of a good fit between the data and the model for the RMSEA and SRMR indicators, respectively (Wang \& Wang, 2012). Comparative Fit Index (CFI) and the Tucker-Lewis Index (TLI) were further used to determine incremental fit. Comparative Fit Index and TLI values higher than 0.90 are considered acceptable (Hair et al., 2010b). Furthermore, two parsimonious fit indices, namely Bayes Information Criteria (BIC) and the Akaike Information Criteria (AIC), that are primarily concerned with the cost-benefit appraisal of fit versus degrees of freedom $(d f)$, were used to compare models. Neither has an absolute interpretation but are meaningful when comparing models - with lower values indicating better fit (Hair et al., 2010a). The composite reliability measurement technique was used to assess internal consistency, as it is superior to Cronbach alpha coefficients when latent variable modelling is used. This is the preferred scientific method in recent literature and is calculated using a formula based on the sum of squares of the standardised loadings and variance of error terms (Raykov, 2009). A cut-off point of 0.70 was considered acceptable (Wang \& Wang, 2012).

To investigate the possibility of Trust (TO and TC) indirectly influencing the relationship between $\mathrm{AL}$ and DC, mediation analysis was performed using a parallel multiple mediator model in PROCESS (Hayes, 2017). The bootstrapping resampling option was set at 10000 samples and statistical significance was determined by two-sided bias-corrected confidence interval levels (CIs) set at a value of $95 \%(<0.05)$.

\section{Ethical considerations}

Ethical approval was granted by the Economic and Management Sciences Research Ethics Committee (EMS-REC) at North-West University. Reference number: NWU-0060920-A4.

\section{Results}

Although there is no single statistical test that could comprehensively test for CMV (Spector, 2006, 2019), we, nevertheless, employed Harman's Single-Factor Test for CMV (Tehseen, Ramayah, \& Sajilan, 2017) to perform an exploratory factor analysis on the data. Four factors emerged that explained $61.42 \%$ of the variance. The first component only explained $41.3 \%$ of the variance, thereby suggesting that CMV was not evident (Tehseen et al., 2017). Furthermore, a CFA in Mplus showed that the single-factor model did not fit the data well, as none of the indicators met the criteria for acceptable model fit $\left(\chi^{2}=1756.65, d f=464, \mathrm{CFI}=0.66\right.$, TLI $=$ $0.63, \mathrm{SRMR}=0.11$ and RMSEA $=0.11$ ). Although none of the results decisively rule out the possibility of $\mathrm{CMV}$, they do suggest that CMV is not an overriding concern in this dataset and for this reason, we did not perform post-hoc CMV correction during subsequent analyses.

\section{Confirmatory factor analysis}

To evaluate the possible relationships between the latent variables, a four-factor measurement model and two alternative models were compared.

In Model 1, AL was specified as a second-order latent variable consisting of four first-order sub-dimensions, TO and TC were both specified as first-order latent variables respectively measured by 11 and 12 directly observed items and DC was specified as a second-order latent factor consisting of three first-order latent components consisting of four items each.

Model 2 was specified similar to Model 1 with the exception that AL was specified as a first-order latent variable measured by means of 14 directly observed variables.

Model 3 consisted of four first-order latent variables in which all constructs were measured by directly observed variables only.

Table 2 was developed by the authors and presents the fit statistics for the three competing measurement models as described above.

For Model 1, the Chi-square test was significant $(p<0.0001)$, with a Chi-square $\left(\chi^{2}\right)$ value of 1855.443 and a $d f$ value of 1114 , indicating that a perfect fit to the data was not attainable. However, Hancock and Mueller (Eds. 2010) recommended that researchers should report multiple fit indices as this measure of fit is known to be oversensitive. According to the alternative fit indices, an approximate fit to the data was attainable: Both TLI and CFI were above the cut-off value of 0.90, RMSEA indicated a close fit $(<0.08, p>0.05)$ and SRMR also indicated a good fit $(<0.08)$.

The results for Model 2 indicated that the Chi-square test was significant $\left(\chi^{2}=1869.270, d f=1118, p<0.0001\right)$ which indicated that a perfect fit was not attainable. The CFI and TLI values supported an approximate fit $(>0.90)$ and this was supported by an acceptable model fit for the RMSEA $(<0.08, p>0.05)$ and SRMR $(<0.08)$ indices.

The Chi-square test, as part of the Model 3 results, was once again significant $\left(\chi^{2}=1960.780, d f=1117, P<0.0001\right)$. The alternative fit indices were again acceptable as represented by TLI and CFI $(>0.90)$ and both the RMSEA $(p>0.05)$ and SRMR values were smaller than 0.08 .

Although acceptable comparative fit indices were indicated for all the three competing models, the CFI (0.925) and TLI 
(0.921) values as well as the lowest AIC value of 40127.694 indicated that Model 1 fitted the data best. In addition, although the $\chi^{2}$ value was significant, it was nevertheless the lowest, and the $d f$ was also the lowest for Model 1 . Furthermore, the RMSEA and SRMR values were also acceptable. Only one indicator (BIC $=40721.009)$ pointed to Model 2 as the better model. When evaluating the findings of all the fit indices in conjunction, Model 1 was chosen as the preferred model. In support of the AIC value that pointed towards this model as the most acceptable, the CFI and TLI fit indices for Model 1 were slightly more ideal than those for the competing models. Another important consideration was that this model also offered the closest resemblance to the factor structures as theory proposes. The standardised results for the observed indicators measuring propensity ranged from 0.40 (lowest) to 0.99 (highest). Item to factor loadings for the scales measuring Relational transparency (ALR), Internalised moral perspective (ALM), Balanced processing (ALB) and Self-awareness (ALS) as related but separable subconstructs of AL ranged from 0.40 (lowest) to 0.81 (highest). Values of items loading onto the two latent variables measuring $\mathrm{TO}$ ranged from 0.66 (lowest) to 0.83 (highest) and for TC values ranged from 0.66 to 0.88 . All indicators in the preferred model (Model 1) loaded statistically significant $(p<0.001)$ onto their respective constructs as expected, establishing the posited relationships amongst indicators and constructs (Hair et al., 2010a).

To see how the $\chi^{2}$ would change between the competing models when compared against the preferred measurement model, Chi-square difference testing had to be performed (Satorra \& Bentler, 1999). Results in the Table 3 provide further support for the preferred model (Model 1), because both competing models (Models 2 and 3) had significant $p$-values, suggesting a significantly worse fit to the data as compared to Model 1.

\section{Testing structural models}

Table 4 reflects the descriptive statistics (e.g. means and standard deviations), Raykov's rho reliability coefficients and Table 5 reflects a correlation matrix. The authors summarised results in Table 4, which indicate that the Raykov's rho coefficients, out of all the measuring instruments, were well above the minimum threshold with values above 0.90 and are thus considered highly reliable.

Table 5 also indicates that the correlation coefficients of the variables were all statistically significant at a $99 \%$ level of certainty. Furthermore, AL was found to be practically and significantly related to TO ( $r=0.48$, medium effect); TC $(r=0.44$, medium effect) and DC ( $r=0.51$, large effect). Trust in organisation was practically and significantly related to TC ( $r=0.59$, large effect) and to DC ( $r=0.71$, large effect). Lastly, DC were practically and significantly related to TC $(r=0.61$, large effect $)$.

The path coefficients for Model 1 are depicted (Figure 1). As evident from Figure 1, AL significantly associates with TO $(\beta=0.499 ; p<0.05), \mathrm{TC}(\beta=0.459 ; p<0.05)$ and DC $(\beta=0.162$; $p<0.05)$. Furthermore, AL explains $24.9 \%$ of the variance in $\mathrm{TO}, 21.1 \%$ of the variance in TC and $55.4 \%$ of the variance in DC. These results provide support for Hypothesis 1 and Hypothesis 2.

\section{Indirect effect}

As a next and final step, mediation analysis was performed employing a parallel multiple mediator model in Process (Hayes, 2017) to assess the potential mediating roles of TO and TC on the linkage between AL and DC. Bootstrapping (5000 samples) was used to construct two-sided bias-corrected $95 \%$ CIs to assess indirect effects. Both TO $(\beta=0.3555, p<0.05$, $95 \% \mathrm{CI}=0.2478-0.4795)$ as well as TC $(\beta=0.1971, p<0.05,95 \%$ $\mathrm{CI}=0.1077-0.3072)$ were significant positive mediators in the relationship between AL and DC. The direct association between $\mathrm{AL}$ and DC decreased but remained significant $(\beta=0.2730, p<0.05)$, showing that AL still associated with

TABLE 3: Chi-square difference test for comparing nested models.

\begin{tabular}{lccc}
\hline Model & $\Delta \boldsymbol{X}^{2}$ & $\Delta d f$ & $p$ \\
\hline 2 vs. 1 & 13.83 & 4 & 0.01 \\
3 vs.1 & 115.99 & 3 & 0.00 \\
\hline
\end{tabular}

TABLE 4: Correlation matrix including means, standard deviations and reliabilities.

\begin{tabular}{lccc}
\hline Variable & $\boldsymbol{M}$ & SD & $\boldsymbol{p}$ \\
\hline 1. ALR & 3.74 & 0.71 & 0.75 \\
2. ALM & 3.61 & 0.63 & 0.71 \\
3. ALB & 3.57 & 0.78 & 0.84 \\
4. ALS & 3.48 & 0.76 & 0.79 \\
5. AL & 3.60 & 0.64 & 0.98 \\
6. TO & 3.64 & 1.25 & 0.93 \\
7. TC & 4.79 & 1.07 & 0.95 \\
8. SE & 4.79 & 1.12 & 0.85 \\
9. SZ & 4.96 & 1.18 & 0.89 \\
10. RC & 4.58 & 1.24 & 0.89 \\
11. DC & 4.78 & 1.10 & 0.97
\end{tabular}

$A L R$, relational transparency; ALM, internalised moral perspective; ALB, balanced processing; ALS, self-awareness; AL, authentic leadership; TO, trust in organisation; TC, trust in colleagues; $\mathrm{SE}$, sensing; SZ, seizing; RC, reconfiguring; $\mathrm{DC}$, dynamic organisational capabilities; M, mean; SD, standard deviation; $\rho$, composite reliability coefficient.

TABLE 2: Fit statistics of competing measurement models.

\begin{tabular}{lcccccccc}
\hline Model & $\boldsymbol{X}^{2}$ & $d f$ & CFI & TLI & RMSEA & SRMR & AIC & BIC \\
\hline 1 & $1855.443^{*}$ & 1114 & 0.925 & 0.921 & $0.046[0.042,0.050] \dagger$ & 0.048 & 40127.694 & 40727.597 \\
2 & $1869.270^{*}$ & 1118 & 0.924 & 0.920 & $0.046[0.043,0.050] \dagger$ & 0.048 & 40136.104 & 40721.009 \\
3 & $1960.780^{*}$ & 1117 & 0.914 & 0.910 & $0.049[0.045,0.053] \dagger$ & 0.048 & 40243.749 & 40832.403 \\
\hline
\end{tabular}

CFI, Comparative Fit Index; TLI, Tucker-Lewis Index; BIC, Bayes Information Criteria; AIC, Akaike Information Criteria; RMSEA, Root Mean Square Error of Approximation; SRMR, Standardised Root Mean Square Residual.

$*, p=0.000$.

$\dagger, 90 \%$ confidence interval $(\mathrm{Cl})$. 
TABLE 5: Correlation matrix.

\begin{tabular}{|c|c|c|c|c|c|c|c|c|c|c|c|}
\hline Variable & 1 & 2 & 3 & 4 & 5 & 6 & 7 & 8 & 9 & 10 & 11 \\
\hline 1. ALR & - & - & - & - & - & - & - & - & - & - & - \\
\hline 2. ALM & $0.92 \div * *$ & - & - & - & - & - & - & - & - & - & - \\
\hline 3. ALB & $0.93+* *$ & $0.93 * * *$ & - & - & - & - & - & - & - & - & - \\
\hline 4. ALS & $0.95 \div * *$ & $0.95 * * *$ & $0.96+* *$ & - & - & - & - & - & - & - & - \\
\hline 5. AL & $0.96 \ddagger * *$ & $0.96 *^{* *}$ & $0.97 \ddagger * *$ & $0.99 \ddagger * *$ & - & - & - & - & - & - & - \\
\hline 6. TO & $0.46 \dagger * *$ & $0.46 \dagger^{* * *}$ & $0.47 \dagger * *$ & $0.48 \dagger * *$ & $0.48 \dagger * *$ & - & - & - & - & - & - \\
\hline 7. TC & $0.42 \dagger * *$ & $0.42 \dagger * *$ & $0.43 \dagger^{* * *}$ & $0.44 \uparrow * *$ & $0.44 \dagger^{* * *}$ & $0.59+* *$ & - & - & - & - & - \\
\hline 8. SE & $0.48 \dagger * *$ & $0.48+* *$ & $0.49 \dagger * *$ & $0.49 \dagger * *$ & $0.50 \dagger * *$ & $0.71+* *$ & $0.61 * * *$ & - & - & - & - \\
\hline 9. SZ & $0.49 \dagger * *$ & $0.48+* *$ & $0.49 \dagger * *$ & $0.50 \uparrow * *$ & $0.51+* *$ & $0.72 \div * *$ & $0.62 \% * *$ & $0.98 \div * *$ & - & - & - \\
\hline 10. RC & $0.43 \dagger * *$ & $0.43 \uparrow * *$ & $0.44 \dagger^{* * *}$ & $0.45 \dagger^{* *}$ & $0.45 \dagger * * *$ & $0.64 t^{* *}$ & $0.55 * * *$ & $0.87 \ddagger * *$ & $0.88 * * *$ & - & - \\
\hline 11. DC & $0.49 \dagger * *$ & $0.49+* *$ & $0.49 \dagger^{* * *}$ & $0.50+* *$ & $0.51+* *$ & $0.71+* *$ & $0.61 * * *$ & $0.98 \div * *$ & $0.99 * * *$ & $0.89 \div * *$ & - \\
\hline
\end{tabular}

ALR, relational transparency; ALM, internalised moral perspective; ALB, balanced processing; ALS, self-awareness; AL, authentic leadership; TO, trust in organisation; TC, trust in colleagues; $\mathrm{SE}$, sensing; SZ, seizing; RC, reconfiguring; $\mathrm{DC}$, dynamic organisational capabilities.

$* *, p<0.01$

$\dagger, r>0.30$.

$\$, r>0.50$.

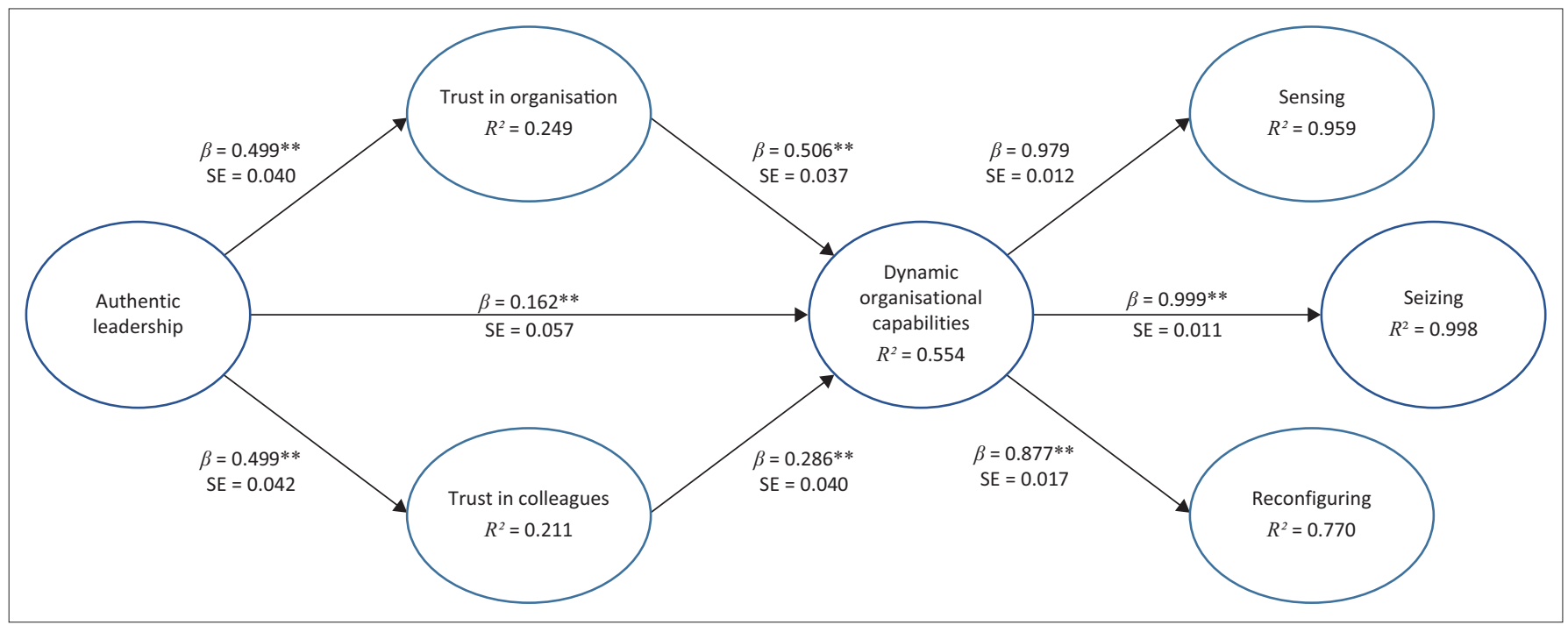

**, $p<0.01$

$\mathrm{SE}$, standard error.

FIGURE 1: Standardised path coefficients for the best-fitting model.

TABLE 6: Regression paths of the research model.

\begin{tabular}{|c|c|c|c|}
\hline Regression relationships & $\begin{array}{l}\text { Standardised } \\
\text { estimate }\end{array}$ & $\begin{array}{l}\text { Standard } \\
\text { error }\end{array}$ & $p$ \\
\hline ALR $\rightarrow$ Authentic leadership & 0.959 & 0.019 & 0.000 \\
\hline ALS $\rightarrow$ Authentic leadership & 0.988 & 0.015 & 0.000 \\
\hline ALM $\rightarrow$ Authentic leadership & 0.961 & 0.018 & 0.000 \\
\hline ALB $\rightarrow$ Authentic leadership & 0.969 & 0.015 & 0.000 \\
\hline $\begin{array}{l}\text { Authentic leadership } \rightarrow \text { Trust in } \\
\text { the organisation }\end{array}$ & 0.499 & 0.040 & 0.000 \\
\hline $\begin{array}{l}\text { Authentic leadership } \rightarrow \text { Trust in } \\
\text { colleagues }\end{array}$ & 0.459 & 0.042 & 0.000 \\
\hline $\begin{array}{l}\text { Authentic leadership } \rightarrow \text { Dynamic } \\
\text { organisational capabilities }\end{array}$ & 0.162 & 0.057 & 0.000 \\
\hline $\begin{array}{l}\text { Trust in the organisation } \rightarrow \text { Dynamic } \\
\text { organisational capabilities }\end{array}$ & 0.506 & 0.037 & 0.000 \\
\hline $\begin{array}{l}\text { Trust in colleagues } \rightarrow \text { Dynamic } \\
\text { organisational capabilities }\end{array}$ & 0.286 & 0.040 & 0.000 \\
\hline SE $\rightarrow$ Dynamic organisational capabilities & 0.979 & 0.012 & 0.000 \\
\hline SZ $\rightarrow$ Dynamic organisational capabilities & 0.999 & 0.011 & 0.000 \\
\hline $\mathrm{RC} \rightarrow$ Dynamic organisational capabilities & 0.877 & 0.017 & 0.000 \\
\hline
\end{tabular}

ALR, relational transparency; ALM, internalised moral perspective; ALB, balanced processing. ALS, self-awareness; SE, sensing; SZ, seizing; RC, reconfiguring.

OC independently of the indirect effect as well. This result provides support for Hypothesis $3 a$ and $b$.

\section{Discussion Outline of the results}

Firstly, the objective of this study was to determine whether the AL style associates with TO, TC and DC amongst a sample of employees from various functions in a manufacturing organisation in South Africa. Secondly, the study aimed to understand whether AL could associate with dynamic capabilities through the underlying mechanism of trust as established amongst colleagues and towards the organisation as focal targets, despite the turbulent economic conditions that are being experienced in the target organisation.

The study was conducted to gain knowledge and understanding of how AL can potentially enhance DC and thereby promote sustainable organisation functioning and possibly even enhance competitiveness despite a precarious business environment.

The SEM results indicated that AL directly and positively associates with TO. This result is in line with previous studies 
on AL that were conducted in a developing country context and which found that AL is a positive predictor of TO (Coxen et al., 2016; Stander et al., 2015). Thus, if employees perceive their leaders to display AL behaviour, they will be more inclined to have TO. Employees will be more inclined to assess processes as fair and to share information whilst experiencing a supportive work environment (Ferres \& Travaglione, 2003). In such a positive work environment, one can expect people to stand together to face challenges, in a very demanding business environment. Ferres and Travaglione (2003) further reinforced this notion by mentioning that when employees trust the organisation, they will positively focus on the effectiveness and sustainability of the organisation. When employees trust their organisation, leaders and/or colleagues, they are more likely to strive for better results in their work (Coxen et al., 2016; Kim, Wang, \& Chen, 2018).

This study also revealed a statistically significant association of AL with TC. This finding might be the result of leaders who are perceived to demonstrate characteristics of authentic leadership and are therefore willing to share information, be objective and who listen to the viewpoints and ideas of subordinates (Neider \& Schriesheim, 2011). According to Avolio and Gardner (2005), authentic leaders are perceived to be self-confident, optimistic, reliable and trustworthy. Additionally, whilst leading by example, authentic leaders encourage followers' potential and strengths, assisting to establish a transparent, healthy and ethical work climate (Gardner et al., 2005; Ilies et al., 2005). When employees trust one another, one can assume that they will be more open in their interaction, confide in one another and approach challenges as a team. It is, nevertheless, interesting to see that such positive results could still be established despite the broader context imposing threats to employees' sustained employment and which would logically be expected to erode trust both in their organisation and their co-workers.

The findings of the study further indicate that AL had a significant direct association with DC. This finding is in line with previous studies suggesting that the way in which senior management behave and send messages would influence the practices and policies that are implemented to develop the capabilities they deem important (Lopez-Cabrales, Bornay-Barrachina, \& Diaz-Fernandez, 2017). To this end, employees who perceive their leaders to exhibit an AL style could experience positive emotions which, in turn, stimulate their creative behaviour in finding alternative solutions for existing challenges (Banks, McCauley, Gardner, \& Guler, 2016; Semedo, Coelho, \& Ribeiro, 2017; Zhou et al., 2014). Lastly, the study found that AL had a significant indirect effect on DC through trust as underlying mechanism. The latter process was particularly facilitated through the promotion of $\mathrm{TO}$ as focal entity, but also to a lesser yet still noteworthy extent through the development of trust amongst colleagues. It can thus be assumed that AL promotes TO and TC, which in turn strengthens the organisation's capability to respond more swiftly to challenges in the sense that it has a better capability to sense and seize opportunities and to reconfigure faster after facing disruptions or dramatic change. This finding resonates with previous studies which found that trust, in general, mediates the relationship between employee attitudes and behaviours (Clapp-Smith, Vogelgesang, \& Avey, 2009; Hassan \& Ahmed, 2011) and that employees are more willing to exert effort if they feel that their organisation cares for them and recognises their efforts, irrespective of the challenges with which they are faced at their workplace (Avolio et al., 2004; Stander et al., 2015).

When the employees in the steel-making sector of the manufacturing industry are thus of the opinion that their employer has their best interests at heart, they will be more inclined to sense opportunities, seize them and play an active role in reconfiguring existing services, processes and products.

The present study makes three theoretical contributions. Firstly, the study contributes to the limited research on AL in extreme uncertain and volatile business environments. It does so by illustrating that AL acts as a positive contributor to support trust and adaptability to challenges. Secondly, it contributes to the leadership literature by showing the relationships within a model where AL is associated with three other specific constructs - TO, TC and DC - which had not been used in such a combination previously, thereby revealing new possibilities for application. Lastly, it contributed to research findings on DC that will feature more in organisational psychology research in future.

\section{Practical implications}

The findings suggest that having authentic leaders in manufacturing organisations could enhance trust in these organisations and amongst employees. Having to face numerous challenges during times of uncertainty, organisations can benefit from authentic leaders who can play an important role in establishing a positive work environment. Furthermore, a work environment consisting of authenticity and trust could lead to employees being more willing to be open to change, share information and find creative ways of solving challenges. Managers could also reinforce the trust relationship by creating an environment in which promises are kept, and colleagues support one another along the journey of achieving set goals. As was demonstrated in this study, trust holds the potential of positively influencing the extent to which the organisation is able to proactively sense opportunities, to act on these (seizing) and to reconfigure after disruption.

It is thus important for the management, employees and human resource departments to understand and take note of the important role that AL plays to promote key aspects such as TO, TC and DC. Lastly, manufacturing organisations may benefit from leadership development programmes focussed on the development of authentic leaders who could contribute to their success and sustainability. The development 
programmes could include modules on how to increase selfawareness and understanding personal values, sound relational skills and how to ensure open and honest communication and its contribution to building trustful relationships, also how to empower and inspire others.

\section{Limitations and recommendations}

This study had several limitations which should be taken into consideration when interpreting the results. Whilst the use of a cross-sectional survey design enabled a more time and costeffective means to establish an initial understanding of associations amongst variables that have not been studied in this combination before, this design also prevented us from drawing definite conclusions about causality and interaction effects in the strict sense. Final conclusions regarding the impact of AL can only be confirmed beyond any doubt through follow-up studies employing a more representative sample and a more complex study design.

The researchers relied on self-report questionnaires, which run the risk of response and common method bias. Although we documented practical measures and technical procedures by which we attempted to address CMV, we acknowledge the views put forward by Spector $(2006,2019)$ that there is no single measure as yet recorded in the existing literature base that could test for CMV in such a comprehensive manner that CMV could be completely ruled out.

Future studies might improve on this aspect, for instance, by introducing a time lag that separates the measurement of the independent and dependent variables or by collecting data from different sources, provided that resources for time and costs would allow for this.

Although theory contains a number of variables that associates with AL, only a few were included in the model used in this study. Futhermore, none of the potentially moderating factors such as tenure and biographic information were tested. Finally, the research was conducted on a single operation in the steel manufacturing industry, limiting the possibility of the generalisation of the findings to other contexts. Extending the scope beyond a single manufacturing organisation and even across sectors, as well as the inclusion of more levels of employment over and above managers, can be beneficial.

\section{Conclusion}

The results of this study support the influential role that AL can play in manufacturing organisations. This finding indicates that entrenching an AL style in manufacturing organisations may promote employees' trust as directed towards the organisation at large, as well as improve the trusting relationship amongst colleagues, which can improve performance as a result of increased willingness to accept leadership direction, more freely sharing information amongst team members and cooperate constructively. Authentic leadership may directly and indirectly, through trust, enhance the organisation's ability to sense, seize and reconfigure opportunities, potentially resulting in improved competitive advantage because of proactive adaptation that is strengthened through such proficiencies. Moreover, although the manufacturing organisation found itself in a volatile and uncertain business environment at the time the study was conducted, the results indicate that an AL approach might lead to positive organisational outcomes despite such challenging circumstances.

\section{Acknowledgements}

The authors would like to acknowledge the manufacturing company and its employees who participated in the study.

\section{Competing interests}

The authors declare that they have no financial or personal relationships that may have inappropriately influenced them in writing this article.

\section{Authors' contributions}

D.J.K. acted as first author (as the article is partially based on his thesis with M.M.H. as promotor and M.W.S. as copromotor). M.M.H. acted as statistical specialist. M.H. and M.W.S. contributed towards conceptualisation, review and editing of the article.

\section{Funding information}

The authors received no financial support for the research, authorship and/or publication of this article.

\section{Data availability}

The authors confirm that the data supporting the findings of this study are available within the article and the raw data that support the findings are available from the corresponding author, M.M.H., upon reasonable request. The main consideration for this was based on the ethical clearance conditions stipulated for this study in order to protect the organisation of interest.

\section{Disclaimer}

The views and opinions expressed in this article are those of the authors and do not necessarily reflect the official policy or position of any affiliated agency of the authors.

\section{References}

Anuradha, T., \& Sujatha, D. (2019). Role of strategic leader in the VUCA world. International Journal of Advance and Innovative Research, 6(1), 72-76. Retrieved from http://iaraedu.com/pdf/ijair-volume-6-issue-1-xxxiii-january-march-2019.pdf

Argote, L., \& Ren, Y. (2012). Transactive memory systems: A microfoundation of dynamic capabilities. Journal of Management Studies, 49(8), 1375-1382. https:// doi.org/10.1111/j.1467-6486.2012.01077.x

Avolio, B.J., \& Gardner, W.L. (2005). Authentic leadership development: Getting to the root of positive forms of leadership. The Leadership Quarterly, 16(3), 315-338. https://doi.org/10.1016/j.leaqua.2005.03.001

Avolio, B.J., Gardner, W.L., Walumbwa, F.O., Luthans, F., \& May, D.R. (2004). Unlocking the mask: A look at the process by which authentic leaders impact follower attitudes and behaviors. The Leadership Quarterly, 15(6), 801-823. https://doi. org/10.1016/j.leaqua.2004.09.003 
Avolio, B.J., \& Walumbwa, F.O. (2014). Authentic leadership theory, research and practice: Steps taken and steps that remain In D.V Day (Ed). The Oxford handbook practice: Steps taken and steps that remain. In D.V. Day (Ed.), The Oxford handbook
of leadership and organizations (pp. 331-356). Oxford: Oxford University Press.

Azanza, G., Moriano, J.A., Molero, F., \& Mangin, J.P.L. (2015). The effects of authentic leadership on turnover intention. Leadership \& Organization Development Journal, 36(8), 955-971. https://doi.org/10.1108/LODJ-03-2014-0056

Bamford, M., Wong, C.A., \& Laschinger, H. (2013). The influence of authentic leadership and areas of worklife on work engagement of registered nurses. Journal of Nursing Management, 21(3), 529-540. https://doi.org/10.1111/j. 1365-2834.2012.01399.x

Banks, G.C., McCauley, K.D., Gardner, W.L., \& Guler, C.E. (2016). A meta-analytic review of authentic and transformational leadership: A test for redundancy. The Leadership Quarterly, 27(4), 634-652. https://doi.org/10.1016/j.leaqua. 2016.02.006

Barreto, I. (2010). Dynamic capabilities: A review of past research and an agenda for the future. Journal of Management, 36(1), 256-280. https://doi.org/10.1177/01 49206309350776

Beddoes-Jones, F., \& Swailes, S. (2015). Authentic leadership: Development of a new three-pillar model. Strategic Human Resources Review, 14(3), 94-99. https://doi. org/10.1108/SHR-04-2015-0032

Begley, P.T. (2006). Self-knowledge, capacity and sensitivity: Prerequisites to authentic leadership by school principals. Journal of Educational Administration, 44(6) 570-589. https://doi.org/10.1108/09578230610704792

Bromiley, P., \& Cummings, L.L. (1996). The organizational trust inventory (OTI): Development and validation. In R. Kramer, \& T.R. Tyler (Eds.), Trust in organizations (pp. 302-330). Thousand Oaks, CA: Sage.

Carroll, T.N., Gormley, T.J., Bilardo, V.J., Burton, R.M., \& Woodman, K.L. (2006) Designing a new organization at NASA: An organization design process using
simulation. Organization Science, 17(2), 202-214. https://doi.org/10.1287/ simulation. Or
orsc.1050.0166

Çeri-Booms, S.M. (2009). An empirical study on transactional, transformational and authentic leaders: Exploring the mediating role of trust in leaders on organizational authentic leaders: Exploring the mediating role of trust in leaders on organizatic
identification (Unpublished doctoral thesis). Istanbul: Yeditepe Unitversity.

Černe, M., Jaklič, M., \& Škerlavaj, M. (2013). Authentic leadership, creativity, and innovation: A multilevel perspective. Leadership, 9(1), 63-85. https://doi. innovation: A multilevel persp
org/10.1177/1742715012455130

Chan, A., Hannah, S.T., \& Gardner, W.L. (2005). Veritable authentic leadership: Emergence, functioning, and impact. In W.L. Gardner, B.J. Avolio, \& F.O Walumbwa (Eds.), Authentic leadership theory and practice: Origins, effects and development (pp. 3-41). Oxford: Oxford University Press.

Clapp-Smith, R., Vogelgesang, G.R., \& Avey, J.B. (2009). Authentic leadership and positive psychological capital: The mediating role of trust at the group level of analysis. Journal of Leadership \& Organizational Studies, 15(3), 227-240. https:// doi.org/10.1177/1548051808326596

Collins, C.J., \& Smith, K.G. (2006). Knowledge exchange and combination: The role of human resource practices in the performance of high-technology firms. Academy of Management Journal, 49(3), 544-560. https://doi.org/10.5465/amj.2006.21794671

Coxen, L., Van der Vaart, L., \& Stander, M.W. (2016). Authentic leadership and organisational citizenship behaviour in the public health care sector: The role of workplace trust. SA Journal of Industrial Psychology, 42(1), 1-13. https://doi. org/10.4102/sajip.v42i1.1364

Dasborough, M.T., \& Ashkanasy, N.M. (2005). Follower emotional reactions to authentic and inauthentic leadership influence. Monographs in Leadership and Management, 3, 281-300.

Fainshmidt, S., \& Frazier, M.L. (2017). What facilitates dynamic capabilities? The role of organizational climate for trust. Long Range Planning, 50(5), 550-566. https:// doi.org/10.1016/j.Irp.2016.05.005

Ferres, N., Connell, J., \& Travaglione, A. (2005). The effect of future redeployment on organization trust. Strategic Change, 14(2), 77-91. https://doi.org/10.1002/jsc.713

Ferres, N., \& Travaglione, T. (2003, December). The development and validation of the workplace trust survey (WTS): Combining qualitative and quantitative methodologies. Paper presented at APROS, Mexico.

Gaddy, J.W., Gonzalez, S.P., Lathan, C.A., \& Graham, P.K. (2017). The perception of authentic leadership on subordinate resilience. Military Behavioral Health, 5(1) 64-72. https://doi.org/10.1080/21635781.2016.1243495

Gardner, W.L., Avolio, B.J., Luthans, F.M., May, D.R., \& Walumbwa, F. (2005). 'Can you see the real me?' A self-based model of authentic leader and followe development. The Leadership Quarterly, 16(3), 343-372. https://doi.org/10.1016/ j.leaqua.2005.03.003

Gardner, W.L., Cogliser, C.C., Davis, K.M., \& Dickens, M.P. (2011). Authentic leadership: A review of the literature and research agenda. The Leadership Quarterly, 22(6), 1120-1145. https://doi.org/10.1016/j.leaqua.2011.09.007

Gilbert, J.A., \& Tang, T.L. (1998). An examination of organizational trust antecedents. Public Personnel Management, 27(3), 321-338. https://doi.org/10.1177/00910 2609802700303

Gill, C., \& Caza, A. (2018). An Investigation of authentic leadership's individual and group influences on follower responses. Journal of Management, 44(2), 530-554. https://doi.org/10.1177/0149206314566461

Gillis, T. (2003). More than a social virtue: Public trust amongst organizations most valuable asset. Communication World, 20(3), 10-12.

Gnizy, I., Baker, W.E., \& Grinstein, A. (2014). Proactive learning culture: A dynamic capability and key success factor for SMEs entering foreign market. International Marketing Review, 31(5), 477-505. https://doi.org/10.1108/ IMR-10-2013-0246
Hair, J.F., Black, W.C., Babin, B.J., \& Anderson, R.E. (2010a). Multivariate data analysis (7th ed.). New York: Pearson.

Hair, J.F., Black, W.C., Babin, B.J., Anderson, R.E., \& Tatham, R.L. (2010b). Multivariate data analysis: A global perspective. New York: Pearson.

Hancock, G.R., \& Mueller, R.O. (Eds.). (2010). The reviewer's guide to quantitative methods in the social sciences. London: Routledge.

Hassan, A., \& Ahmed, F. (2011). Authentic leadership, trust and work engagement. International Journal of Human and Social Sciences, 6(3), 164-170.

Hayes, A.F. (2017). Introduction to mediation, moderation, and conditional process analysis: A regression-based approach (2nd edn.). Guilford Press.

Helfat, C.E., Finkelstein, S., Mitchell, W., Peteraf, M.A., Singh, H., Teece, D.J., \& Winter, S.G. (2007). Dynamic capabilities: Understanding strategic change in organizations (1st edn.). Wiley-Blackwell.

Helfat, C.E., \& Peteraf, M.A. (2015). Managerial cognitive capabilities and the microfoundations of dynamic capabilities. Strategic Management Journal, 36(6), 831-850. https://doi.org/10.1002/smj.2247

Henryhand, C.J. (2009). The effect of employee recognition and employee engagement on job satisfaction and intent to leave in the public sector (Doctoral thesis). Capella University. Retrieved from https://search.proquest.com/openv ew/9f1df00711437559b64536f4b482a7af/1?pq-origsite=gscholar\&cbl=18750 \&diss $=y$

Hung, R.Y.Y., Yang, B., Lien, B.Y.H., McLean, G.N., \& Kuo, Y.M. (2010). Dynamic capability: Impact of process alignment and organizational learning culture on performance. Journal of World Business, 45(3), 285-294. https://doi. org/10.1016/j.jwb.2009.09.003

Ilies, R., Morgeson, F.P., \& Nahrgang, J.D. (2005). Authentic leadership and eudaemonic well-being: Understanding leader-follower outcomes. The Leadership Quarterly, 16(3), 373-394. https://doi.org/10.1016/j.leaqua.2005.03.002

Islam, M.N., Furuoka, F., \& Idris, A. (2020). The impact of trust in leadership on organizational transformation. Global Business and Organizational Excellence, 39(4), 1-10. https://doi.org/10.1002/joe.22001

Joo, B., \& Jo, S. (2017). The effects of perceived authentic leadership and core selfevaluations on organizational citizenship behavior: The role of psychological empowerment as a partial mediator. Leadership \& Organization Developmen Journal, 38(3), 463-481. https://doi.org/10.1108/LODJ-11-2015-0254

Khan, S.N. (2010). Impact of authentic leaders on organization performance. International Journal of Business and Management, 5(12), 167-172. https://doi. org/10.5539/ijbm.v5n12p167

Kim, T.Y., Wang, J., \& Chen, J. (2018). Mutual trust between leader and subordinate and employee outcomes. Journal of Business Ethics, 149(4), 945-958. https://doi. org/10.1007/s10551-016-3093-y

Kirkman, B.L., \& Rosen, B. (1999). Beyond self-management: The antecedents and consequences of team empowerment. Academy of Management Journal, 42(1), 58-74. https://doi.org/10.2307/256874

Kleinbaum, A., \& Stuart, T. (2014). Network responsiveness: The social structural microfoundations of dynamic capabilities. The Academy of Management Perspectives, 28(4), 353-367. https://doi.org/10.5465/amp.2013.0096

Laguna, M., Walachowska, K., Gorgievski-Duijvesteijn, M.J., \& Moriano, J.A. (2019). Authentic leadership and employees' innovative behaviour: A multilevel investigation in three countries. International Journal of Environmental Research and Public Health, 16(21), 4201. https://doi.org/10.3390/ ijerph16214201

Leroy, H., Palanski, M.E., \& Simons, T. (2012). Authentic leadership and behavioral integrity as drivers of follower commitment and performance. Journal of Business Ethics, 107, 255-264. https://doi.org/10.1007/s10551-011-1036-1

Lewicki, R., McAllister, D., \& Bies, R. (1998). Trust and distrust: New relationships and realities. Academy of Management Review, 23(3), 438-458. https://doi. org/10.5465/amr.1998.926620

Lopez-Cabrales, A., Bornay-Barrachina, M., \& Diaz-Fernandez, M. (2017). Leadership and dynamic capabilities: The role of HR systems. Personne Review, 46(2), 255-276. https://doi.org/10.1108/PR-05-2015-0146

Men, L.R., \& Stacks, D. (2014). The effects of authentic leadership on strategic internal communication and employee-organization relationships. Journal of Public Relations Research, 26(4), 301-324. https://doi.org/10.1080/106272 6X.2014.908720

Miniotaite, A., \& Buciuniene, I. (2013). Explaining authentic leadership work outcomes from the perspective of a self-determination theory. Management of Organizations: Systematic Research, 65, 63-75. https://doi.org/10.7220/ MOSR.1392.1142.2013.65.5

Muceldili, B., Turan, H., \& Erdil, O. (2013). The influence of authentic leadership on creativity and innovativeness. Procedia-Social and Behavioral Sciences, 99(6), 673-681. https://doi.org/10.1016/j.sbspro.2013.10.538

Muldoon, J., Bendickson, J.S., \& Mayherne, C.F. (2019). Micro-foundations of resources, capabilities, and firm performance: A look at LMX. Small Business resources, capabilities, and fitute Journal, 19(1), 49-68.
Instion

Munyaka, S.A., Boshoff, A.B., Pietersen, J., \& Snelgar, R. (2017). The relationships between authentic leadership, psychological capital, psychological climate, team commitment and intention to quit. SA Journal of Industrial Psychology, 43(1) 1-11. https://doi.org/10.4102/sajip.v43i0.1430

Muthén, L.K., \& Muthén, B.O. (1998-2019). Mplus user's guide (8th ed.). Los Angeles, CA: Muthén \& Muthén.

Neider, L.L., \& Schriesheim, C.A. (2011). The Authentic Leadership Inventory (ALI): Development and empirical tests. The Leadership Quarterly, 22(6), 1041-1198. https://doi.org/10.1016/j.leaqua.2011.09.008 
Pablo, A., Reay, T., Dewald, J.R., \& Casebeer, A.L. (2007). Identifying, enabling and managing dynamic capabilities in the public sector Journal of Management managing dynamic capabilities in the public sector. Journal of Manage
Studies, 44(5), 687-708. https://doi.org/10.1111/j.1467-6486.2006.00675.x

Paliszkiewicz, J., \& Koohang, A. (2013). Organizational trust as a foundation for knowledge sharing and its influence on organizational performance. The Online Journal of Applied Knowledge Management, 1(2), 116-127.

Raghuramapatruni, R., \& Kosuri, S.R. (2017). The Straits of Success in a VUCA World. IOSR Journal of Business and Management, 17(2), 16-22.

Rawung, F.H., Wuryaningrat, N.F., \& Elvinit, L.E. (2015). The influence of transformational and transactional leadership on knowledge sharing: An empirical study on small and medium businesses in Indonesia. Asian Academy of Management Journal, 20(1), 123-145.

Raykov, T. (2009). Evaluation of scale reliability for unidimensional measures using latent variable modeling. Measurement and Evaluation in Counseling and Development, 42(3), 223-232. https://doi.org/10.1177/0748175609344096

Rego, A., Sousa, F., Marques, C., \& Cunha, M.P. (2012). Authentic leadership promoting employees' psychological capital and creativity. Journal of Business Research, 65(3), 429-437. https://doi.org/10.1016/j.jbusres.2011.10.003

Rego, A., Sousa, F., Marques, C., \& Cunha, M.P. (2014). Hope and positive affect mediating the authentic leadership and creativity relationship. Journal of Business
Research, 67(2), 200-210. https://doi.org/10.1016/j.jbusres.2012.10.003

Ribeiro, N., Duarte, A., Filipe, R., \& Torres de Oliveira, R. (2020). How authentic leadership promotes individual creativity: The mediating role of affective commitment. Journal of Leadership and Organizational Studies, 27(2), 189-202. https://doi.org/10.1177/1548051819842796

Robbins, S.P., Judge, T.A., Odendaal, A., \& Roodt, G. (2016). Organisational behaviour: Global and southern perspectives ( $3 \mathrm{rd}$ ed.). Cape Town: Pearson.

Saruhan, N. (2013). Organizational Change: The effects of trust in organization and psychological capital during change process. Journal of Business Economics and Finance, 2(3), 13-35.

Satorra, A., \& Bentler, P.M. (1999). A scaled difference chi-square test statistic for moment structure analysis. UPF Working Paper No. 412. Retrieved from https:// papers.ssrn.com/sol3/papers.cfm?abstract_id=199064

Schreyögg, G., \& Sydow, J. (2010). Crossroads-organizing for fluidity? Dilemmas of new organizational forms. Organization Science, 21(6), 1251-1262. https://doi. org/10.1287/orsc.1100.0561

Semedo, A.S., Coelho, A., \& Ribeiro, N. (2017). Authentic leadership and creativity: The mediating role of happiness. International Journal of Organizational Analysis, 25(3), 395-412. https://doi.org/10.1108/IJOA-03-2016-0994

Spector, P.E. (2006). Method variance in organizational research: Truth or urban legend? Organizational Research Methods, 9(2), 221-232. https://doi. org/10.1177/1094428105284955

Spector, P.E. (2019). Do not cross me: Optimising the use of cross-sectional designs. Journal of Business Psychology, 34(3), 125-137. https://doi.org/10.1007/s10869018-09613-8

Stander, F.W., De Beer, L.T., \& Stander, M.W. (2015). Authentic leadership as a source of optimism, trust in the organisation and work engagement in the public health care sector. SA Journal of Human Resource Management, 13(1), 1-12. https://doi. org/10.4102/sajhrm.v13i1.675
Statistics South Africa. (2020). Gross domestic product: Second quarter 2020. Statistical release P0441. Retrieved from http://www.statssa.gov.za/publications/ P0441/P04412ndQuarter2020.pdf

Tabak, A., Polat, M., Çoşar, S., \& Türköz, T. (2013). A Research on the consequences of authentic leadership. Journal Review of Social, Economic and Administrative Studies, 27(2), 65-88. https://doi.org/10.21773/boun.27.2.4

Teece, D.J. (2014). The foundations of enterprise performance: Dynamic and ordinary capabilities in an (economic) theory of firms. Academy of Management Perspectives, 28(4), 328-352. https://doi.org/10.5465/amp.2013.0116

Teece, D.J., Pisano, G., \& Shuen, A. (1997). Dynamic capabilities and strategic management. Strategic Management Journal, 18(7), 509-533. https://doi. org/10.1002/(SICI)1097-0266(199708)18:7<509::AID-SMJ882>3.0.CO;2-Z

Tehseen, S., Ramayah, T., \& Sajilan, S. (2017). Testing and controlling for Common Method Variance: A review of available methods. Journal of Management Sciences, 4(2), 146-175. https://doi.org/10.20547/jms.2014.1704202

Thanetsunthorn, N., \& Wuthisatian, R. (2020). Trust and culture: Applications for organization development. Organization Development Journal, 38(1), 33-43.

Towsen, T., Stander, M.W., \& Van der Vaart, L. (2020). The relationship between authentic leadership, psychological empowerment, role clarity, and work engagement: Evidence from South Africa. Frontiers in Psychology, 11(1973), 1-13. https://doi.org/10.3389/fpsyg.2020.01973

Villena, V.H., Choi, T.Y., \& Revilla, E. (2019). Revisiting interorganizational trust: Is more always better or could more be worse? Journal of Management, 45(2), 752-785. https://doi.org/10.1177/0149206316680031

Walumbwa, F.O., Avolio, B.J., Gardner, W.L., Wernsing, T.S., \& Peterson, S.J. (2008). Authentic leadership: Development and validation of a theory-based measure. Journal of Management, 34(1), 89-126. https://doi.org/10.1177/ 0149206307308913

Wang, D.S., \& Hsieh, C.C. (2013). The effect of authentic leadership on employee trust and employee engagement. International Journal of Social Behavior and Personality, 41(4), 613-624. https://doi.org/10.2224/sbp.2013.41.4.613

Wang, H., Sui, Y., Luthans, F., Wang, D., \& Wu, Y. (2014). Impact of authentic leadership on performance: Role of followers' positive psychological capital and relational processes. Journal of Organizational Behavior, 35(1), 5-21. https://doi. org/10.1002/job.1850

Wang, J., \& Wang, X. (2012). Structural equation modeling: Applications using Mplus (1st ed.). New York: Wiley.

Wang, J., \& Wang, X. (2020). Structural equation modeling: Applications using Mplus (2nd ed.). New York: Wiley.

Wilden, R., Gudergan, S.P., Nielsen, B., \& Lings, I. (2013). Dynamic capabilities and performance: Strategy, structure and environment. Long Range Planning, 46(1), 72-96. https://doi.org/10.1016/j.Irp.2012.12.001

Zeb, A., Abdullah, N.H., Hussain, A., \& Safi, A. (2019), Authentic leadership, knowledge sharing, and employees' creativity. Management Research Review, 43(6), 669-690. https://doi.org/10.1108/MRR-04-2019-0164

Zhou, J., Ma, Y., Cheng, W., \& Xia, B. (2014). Mediating role of employee emotions in the relationship between authentic leadership and employee innovation. Social Behavior and Personality, 42(8), 1267-1278. https://doi.org/10.2224/ sbp.2014.42.8.1267 